\title{
BMJ Global Health Solving the problem of access to cardiovascular medicines: revolving fund pharmacy models in rural western Kenya
}

\author{
Dan N Tran (1) , 1,2,3 Imran Manji, ${ }^{4}$ Benson Njuguna, ${ }^{4}$ Jemima Kamano, ${ }^{3,5}$
} Jeremiah Laktabai, ${ }^{3,6}$ Edith Tonui, ${ }^{7}$ Rajesh Vedanthan (D) , ${ }^{3,8}$ Sonak Pastakia (1) ${ }^{1,2,3}$

To cite: Tran DN, Manji I, Njuguna B, et al. Solving the problem of access to cardiovascular medicines: revolving fund pharmacy models in rural western Kenya. BMJ Global Health 2020;5:e003116. doi:10.1136/ bmjgh-2020-003116

Handling editor Seye Abimbola

DNT and IM contributed equally. $\mathrm{RV}$ and SP contributed equally.

DNT and IM are joint first authors.

$\mathrm{RV}$ and SP are joint senior authors.

Received 9 June 2020 Revised 17 September 2020 Accepted 20 September 2020

\section{ABSTRACT}

Availability of medicines for treatment of cardiovascular disease (CVD) is low in low-income and middle-income countries (LMIC). Supply chain models to improve the availability of quality CVD medicines in LMIC communities are urgently required. Our team established contextualised revolving fund pharmacies (RFPs) in rural western Kenya, whereby an initial stock of essential medicines was obtained through donations or purchase and then sold at a small mark-up price sufficient to replenish drug stock and ensure sustainability. In response to different contexts and levels of the public health system in Kenya (eg, primary versus tertiary), we developed and implemented three contextualised models of RFPs over the past decade, creating a network of 72 RFPs across western Kenya, that supplied 22 categories of CVD medicines and increased availability of essential CVD medications from $<30 \%$ to $90 \%$ or higher. In one representative year, we were able to successfully supply 5793981 units of CVD and diabetes medicines to patients in western Kenya. The estimated programme running cost was US\$6.5-25 per patient, serving as a useful benchmark for public governments to invest in medication supply chain systems in LMICs going forward. One important lesson that we have learnt from implementing three different RFP models over the past 10 years has been that each model has its own advantages and disadvantages, and we must continue to stay nimble and modify as needed to determine the optimal supply chain model while ensuring consistent access to essential CVD medications for patients living in these settings.

\section{INTRODUCTION}

(c) Author(s) (or their employer(s)) 2020. Re-use permitted under CC BY-NC. No commercial re-use. See rights and permissions. Published by BMJ.

For numbered affiliations see end of article.

Correspondence to

Dr Dan N Tran;

tran.nk.tina@gmail.com
Availability of medicines for treatment of cardiovascular disease (CVD) is still considered suboptimal across many low-income and middle-income countries (LMIC) worldwide. ${ }^{1}$ In rural communities of low-income and lower-middle income countries, availability of CVD medicines was estimated to be between $3 \%$ and $37 \%$, with up to $60 \%$ of these medicines being unaffordable to patients who need them. ${ }^{1}$ Limited access to

\section{Key questions}

What is already known?

- Availability of medicines for treatment of cardiovascular disease (CVD) is still suboptimal across many rural communities of low-income and middle-income countries (LMIC) worldwide.

- Limited access to CVD medicines for LMIC patient populations significantly hinders adherence and increases morbidity and mortality, with subsequent detrimental impact on economic productivity and development, poverty and inequality.

- The revolving fund pharmacy (RFP) concept represents a promising, pragmatic, affordable and sustainable supply chain model for CVD medicines.

What are the new findings?

- We developed and implemented three contextualised models of RFPs over the past decade, creating a network of 72 RFPs across western Kenya that supplied 22 categories of CVD medicines and increased availability of essential CVD medications from $<30 \%$ to $90 \%$ or higher.

- In one representative year, we were able to successfully supply 5793981 units of CVD and diabetes medicines to patients in western Kenya.

- The estimated programme running cost was US\$6.5-25 per patient, serving as a useful benchmark for public governments to invest in medication supply chain systems in LMICs going forward.

What do the new findings imply?

- The RFP model has the potential to significantly improve access to CVD medicines for patients and can be adapted and implemented in other similar low-resource settings.

- It is important to note that each supply chain model has its own advantages and disadvantages, and we must continue to stay nimble and modify as needed to determine the optimal supply chain model while ensuring consistent access to essential CVD medications for patients living in these settings. 
CVD medicines for LMIC patient populations significantly hinders adherence ${ }^{2}$ and increases morbidity and mortality, ${ }^{3-5}$ with subsequent detrimental impact on economic productivity and development, poverty and inequality. ${ }^{6-11}$

The search for programmes to provide cost-effective CVD prevention and treatment services in LMICs has intensified over the last decade, but gaps persist in ensuring reliable access to CVD medicines in resourcelimited settings, particularly in rural LMIC communities. $^{2}{ }^{12-15}$ In our practice setting in rural western Kenya, the availability of CVD medicines is low, with availability of originator-brand CVD medicines reported to be as low as $<5 \%$ and availability of generic CVD medicines was $<30 \%$ in the public sector, ${ }^{16}$ while the rise of falsified and substandard medicines remained concerning to both consumers and the health system. ${ }^{17}$ These challenges are not unique to Kenya and are present in LMICs worldwide. Thus, contextualised supply chain models to deliver consistent and quality CVD medicines in Kenya and similar LMIC communities are urgently required. ${ }^{2}{ }^{18}$

The revolving drug fund concept represents a promising, pragmatic, affordable and sustainable supply chain model for CVD medicines. In this model, an initial stock of essential medicines is obtained through seed funding and then sold at a small mark-up price that is sufficient to replenish drug stock and ensure sustainability of the model operation. ${ }^{19} 20$ Our investigator team has leveraged this concept to successfully establish revolving fund pharmacies (RFPs) as a backup supply chain system for the Kenya Ministry of Health $(\mathrm{MOH})$, specifically in governmentowned/public sector health facilities. Starting with three pilot RFPs, we have previously reported an increase in availability of essential medicines from $<10 \%$ pre-RFP to $>90 \%$ post-RFP. ${ }^{18}$ Despite this success, we recognised that our initial efforts did not immediately reach the more remote rural areas where a significant proportion of our CVD patient population reside. Therefore, over the past 9 years, we have continued to refine and build on our pilot success to fill in this care gap, specifically in public/governmental health facilities. Our previously published RFP evaluation was primarily limited to nonCVD essential medicines. ${ }^{18}$ Thus, this current evaluation focuses specifically on how the RFP has been expanded to address the needs for CVD and diabetes mellitus essential medicines and access.

In this paper, we describe our experience with extending the RFP model to the lower-level public-sector health facilities in the most rural areas of our western Kenyan catchment area, in order to deliver medicines for CVD and diabetes mellitus. We also describe how we adjusted and calibrated according to local contexts, ultimately remaining nimble and developing three different models that were context-specific and allowed for successful supply of CVD medicines. In addition, we highlight the rationale for using each model in its respective context, an in-depth description of operations and costs and a summary of impact on increasing medication access. Last, we reflect on lessons learnt and future plans in expanding our RFPs to other similar low-resource settings.

\section{METHODS}

\section{Programme setting}

The Academic Model Providing Access to Healthcare (AMPATH) programme is an academic partnership between Moi University College of Health Sciences (MUCHS), Moi Teaching and Referral Hospital and a consortium of North American universities. ${ }^{21}$ In 2011, AMPATH established a chronic disease management (CDM) programme in collaboration with the Kenya $\mathrm{MOH}$ to provide care for non-communicable diseases such as hypertension and diabetes across seven different counties in western Kenya, and we have enrolled over 50000 patients since that time. ${ }^{17}$ The RFPs have played a vital role within the AMPATH CDM programme by ensuring reliable access to medication supplies for these patients across $\mathrm{MOH}$-supported county health facilities in rural western Kenya. ${ }^{22}$

The original Model 1 RFPs were first established in 2011 to address the inadequate access to essential medicines, particularly for patients living with chronic diseases at the time. ${ }^{18}$ This model was referred to as the 'communitymanaged RFP model' due to its significant engagement with community stakeholders in its governance and financial management. During the course of implementation over the past decade, our programme recognised that we needed to be flexible and compliant with local contexts in terms of geographical area, supervision, operation, financial accountancy and patient population. As a result, we developed two additional RFP models to address those needs. Model 2 RFPs were known as 'AMPATH-managed RFPs', having their governance and finances being overseen by AMPATH, while Model 3 RFPs were 'facility-managed RFPs', with their operation being managed directly by health facilities in which these RFPs existed. Thus far, we have implemented a network of 72 RFPs across all levels of the health system in Kenya, from level 1 (community), level 2 (health dispensaries), level 3 (health centres), level 4 (subcounty hospitals), level 5 (county hospitals), to level 6 (tertiary referral hospitals). Currently, we have 15 community-managed RFPs (Model 1), 7 AMPATH-managed RFPs (Model 2) and 50 facilitymanaged RFPs (Model 3).

\section{Data sources}

This is a retrospective study using administrative data reports that were collected as part of the usual operation of the RFPs in a predefined time period between 1 April 2011 through 31 December 2018. Our three primary data sources included (1) memorandum of understanding (MOU) agreements with the county health facilities (2011-2018), (2) inventory audit reports (2018) and (3) financial reports (2011-2018). First, MOU agreements provided historic descriptions of each of our 
RFP models, detailing how operational guidance, financial details, reporting mechanisms, accountability and governance were established. Second, inventory audit reports provided quantitative description of medication supply (defined as total quantity of medications sold) and availability (defined as average percentage of days per year when the audited medications were present at health facilities where the RFPs operated). RFP inventory audits are carried out routinely for supervision purposes and typically involve doing a physical stocktake, reconciling cash collections, tallying prescriptions served and calculating revenue earned at each RFP site. On average, inventory audits are carried out on a quarterly basis, but this can be as frequent as two times a month if the RFP is new. Inventory audit reports include information related to medication supply (for medications supplied to the RFP) and availability (for selected tracer medications) per reporting period. We purposefully chose to report data from 2018 for two reasons. We began our data collection process in 2019. As a result, we chose to report data up to end of 2018 to have a complete annual/calendar-year dataset. We could have reported data from 2011 up to 2018. However, our RFP programme is very much based on an iterative process over a period of almost 10 years. During this time period, new pharmacies were built while some pharmacies were closed and/or acquired by larger RFPs to more efficiently operate. Meanwhile, it took several years for us to build a rigorous data reporting system; as a result, there is a data scarcity in the first few years of our operation. We believe that our data quality in the year of 2018 best represents the current status of where our programme is standing at the moment. Last, financial reports for each of the three RFP models were used to estimate costs associated with the establishment of each RFP site, including setup costs, running costs and administrative costs.

\section{Data analysis}

We qualitatively reviewed established MOUs and categorised the content of all MOUs for each RFP model into governance, operations and inventory, accounting and financial reporting mechanisms. Two pharmacists (IM and DT) worked together to review all inventory audit reports. On average, there were a total of four audit reports per RFP site in 2018. Essential CVD medicines were selected from the list of medications audited and categorised based on (1) pharmacological categories, (2) level of health facility at which medications were dispensed and (3) the model of the RFP. We calculated supply by summating the number of medication units (ie, tablets, capsules or vials) supplied and dispensed for each medicine over a 12-month period.

For availability, frequencies were calculated for each medicine and averaged over a period of 12 months. We included availability data for only Models 1 and 2 as these audit reports were most consistently available during our predefined time period. Model 3 reports were not consistently available as these audits were not formally carried out on a scheduled basis by MOH health facilities; therefore, Model 3 was not included in the availability analysis.

Historical financial reports for all RFPs at the time of their establishment and financial reports in the year of 2018 were compiled. For each RFP model, we recorded one-time setup cost and annual running costs per pharmacy in that model. One-time setting-up costs included facility renovation, seed stock of drugs and travel costs. Annual running costs included personnel, supervision, transportation, cost waivers for indigent patients, programme leadership and management. Individual pharmacy costs were summated per RFP, and total costs were calculated by multiplying individual costs per pharmacy by the total number of RFPs in each model. Total costs were reported in terms of total setting-up cost in the first year of operation (ie, one-time cost) and total running cost per year in subsequent years per RFP model. To estimate the running cost per patient, we divided the total running costs by an estimated number of patients receiving one medication unit per day in a year.

\section{Patient and public involvement}

Because this was a retrospective using programmatic and administrative data reports, patients or the public were not directly involved in the design or conduct of the research. However, our patients have been intimately engaged and their needs have been the inspiration of the implementation of the RFP model since the inception of this programme in 2011. Results from this published study will be reported and disseminated widely with the local health facility in-charges, the AMPATH Leadership, as well as the Ministry of Health of Kenya in order to advocate for further expansion of this impactful supply chain model to improve access to CVD and diabetes medications for the public.

\section{RESULTS}

\section{Description of revolving fund pharmacy (RFP) models}

We describe similarities and differences for RFP Models $1-3$ in detail to shed light on the evolution of the different models we have developed as well as how they are managed. Table 1 provides a summary of this information.

\section{Model 1: Community-managed RFP}

This was the original RFP model in which a separate and parallel pharmacy was set up within the County health facility, as a backup to the existing facility pharmacy in case of stockouts and patients were not able to access essential medicines from the facility pharmacy. While we were working to strengthen the county medication supplies through the main facility pharmacies, we recognised that this would take time to fully implement. Therefore, the Model 1 RFPs formed a backup system to address immediate medication access needs while we continued to work with county governments and facilities to address systemic supply chain challenges. As a result, the following stakeholders, the $\mathrm{MOH}$, the facility 
Table 1 Summary of all RFP Models 1-3

\begin{tabular}{|c|c|c|c|}
\hline $\begin{array}{l}\text { General characteristics } \\
\text { and overall management } \\
\text { mechanisms }\end{array}$ & $\begin{array}{l}\text { Model } 1 \\
\text { Community-managed RFP }\end{array}$ & $\begin{array}{l}\text { Model } 2 \\
\text { AMPATH-managed RFP }\end{array}$ & $\begin{array}{l}\text { Model } 3 \\
\text { Facility-managed RFP }\end{array}$ \\
\hline Year established & 2011 & 2012 & 2013 \\
\hline $\begin{array}{l}\text { Total number of RFPs } \\
\text { established as of } 2018\end{array}$ & 15 & 7 & 50 \\
\hline $\begin{array}{l}\text { Total number of health } \\
\text { facilities with RFPs by } \\
\text { levels of care (level 1-6)* } \\
\text { as of } 2018\end{array}$ & $\begin{array}{l}\text { Level 2: } 3 \text { facilities } \\
\text { Level 3: } 5 \text { facilities } \\
\text { Level 4: } 6 \text { facilities } \\
\text { Level 5: } 1 \text { facility }\end{array}$ & $\begin{array}{l}\text { Level 3: } 1 \text { facility } \\
\text { Level 4: } 3 \text { facilities } \\
\text { Level 5: } 2 \text { facilities } \\
\text { Level 6: } 1 \text { facility }\end{array}$ & $\begin{array}{l}\text { Level 2: } 31 \text { facilities } \\
\text { Level 3: } 11 \text { facilities } \\
\text { Level 4: } 8 \text { facilities }\end{array}$ \\
\hline \multirow{2}{*}{$\begin{array}{l}\text { Cumulative number of } \\
\text { patients served between } \\
2011 \text { and } 2018\end{array}$} & $\begin{array}{l}\text { Hypertension: } 10622 \\
\text { Diabetes: } 4231\end{array}$ & $\begin{array}{l}\text { Hypertension: } 13916 \\
\text { Diabetes: } 10943\end{array}$ & $\begin{array}{l}\text { Hypertension: } 11239 \\
\text { Diabetes: } 2598\end{array}$ \\
\hline & Total: 14853 & Total: 24859 & Total: 13837 \\
\hline Operation & $\begin{array}{l}\text { Existing MOH pharmaceutical } \\
\text { technologist } \\
\text { OR } \\
\text { Occasional newly RFP-hired } \\
\text { pharmaceutical technologist }\end{array}$ & $\begin{array}{l}\text { New RFP-hired } \\
\text { pharmaceutical technologist }\end{array}$ & $\begin{array}{l}\text { Nurse in-charge or clinical } \\
\text { officer in-charge } \\
\text { OR } \\
\text { Occasional support from the } \\
\text { AMPATH CDM programme }\end{array}$ \\
\hline Medicine procurement & $\begin{array}{l}\text { Direct bulk procurement through } \\
\text { AMPATH programme }\end{array}$ & $\begin{array}{l}\text { Direct bulk procurement through } \\
\text { AMPATH programme }\end{array}$ & $\begin{array}{l}\text { Indirectly through regional } \\
\text { Model } 1 \text { and } 2 \text { RFPs }\end{array}$ \\
\hline Management of revenue & $\begin{array}{l}\text { Jointly by County } \mathrm{MOH} \text {, local } \\
\text { community and AMPATH }\end{array}$ & $\begin{array}{l}\text { Only by AMPATH Research and } \\
\text { Sponsored Projects Office }\end{array}$ & Only by health facility \\
\hline
\end{tabular}

*Level $1=$ community-based care, Level 2=health dispensaries, Level 3=health centres, Level 4=subcounty hospitals, Level 5=county hospitals, Level 6=tertiary/referral hospitals.

AMPATH, The Academic Model Providing Access to Healthcare; CDM, chronic disease management; RFP, revolving fund pharmacy.

in-charge personnel, local community representatives and AMPATH, managed the RFPs. ${ }^{18}$ Drug procurement was done centrally by the AMPATH programme to get the best possible pricing for medicines through bulk procurement. Because Kenyan national health insurance did not cover outpatient CVD medication costs, pharmacies within the public-sector health system charged copays for medications. Thus, the community-managed RFP model also charged copays for medications, but with a minimal average 10\% markup above the facility price. The markup served two purposes: (1) we ensured preferential refill of drugs in the county pharmacy if in stock, hence encouraging the RFP's sustainability and growth rather than competition and (2) the additional
RFP revenue helped maintain the pharmacy and offset other expenses. For a small subset of patients who were unable to afford copays, a waiver system was in place to support those patients. Essentially, a social worker independently assessed a patient's ability to pay and recommended a full or partial waiver, where applicable. ${ }^{18}$ Revenue was collected into a bank account separate from the health facility account and representatives from each stakeholder were assigned as joint signatories to the account. In this model, the pharmacy had a full formulary of essential medicines and was run daily either by an existing facility pharmaceutical technologist or an RFPhired pharmaceutical technologist using the revenue generated from the sale of medicines. These RFPs were 
supervised by staff from AMPATH who routinely carry out stocktakes and financial audits. During the initial evaluation of RFP implementation, the availability of essential medicines improved from an average of $30 \%-40 \%$ to $>90 \% .^{18}$ In the period of the current analysis (2018), this model was run in 15 facilities within the AMPATH catchment area. These facilities had 10662 patients who were hypertensive and 4231 patients who were diabetic cumulatively enrolled into care between 2011 and 2018 .

\section{Model 2: AMPATH-managed RFP}

Due to restrictions in a few counties with regard to the ability to open separate accounts for financial management, in 2012, our programme developed the second RFP model, in which the AMPATH programme directly managed the RFP's finances. The other stakeholders (ie, county, local community representatives) were still involved in the management of other aspects of the pharmacy, such as staffing, inventory control and drug formulary determination similar to Model 1 . Drug procurement was also done centrally by the AMPATH programme in order to get the best possible pricing for medicines through bulk procurement. Similar to Model 1, Model 2 RFPs were also set up as a separate and parallel to the health facility pharmacy, for the same reason as described above. However, the revenue collected was deposited into an account administered by AMPATH's Research and Sponsored Projects Office. In 2018, there were seven RFPs that used this model of operation. Facilities using this model had 13916 patients who were hypertensive and 10943 patients who were diabetic cumulatively enrolled into care between 2012 and 2018.

In both Models 1 and 2, there were significant operating costs associated with running the pharmacies including staff, copay waivers, supervisory audits and transportation of medicines and supervisors. For this reason, these models could only be implemented in facilities that had a high patient volume to generate sufficient revenues to sustain the fixed operating costs of the RFP. It was difficult to implement these models with relatively higher fixed costs in facilities with lower patient volumes, which were generally located in the more rural areas in closer proximity to communities and villages. Because of AMPATH's efforts to bring care as close to patients as possible, another contextualised approach was needed to increase medication access in remote rural areas with limited patient densities. Model 3 was developed to address this need.

\section{Model 3: Facility-managed RFP}

In 2013, as our AMPATH CDM programme expanded its patient care effort to community-based and facility-based care in the most rural community and the lowest-level health facilities (ie, levels 1-3), we needed to develop a supply chain system that could serve patients living in close proximity to those very rural health facilities. ${ }^{172324}$ At the time that AMPATH expanded its CDM programme to the more rural areas and geographically decentralised health facilities, historical $\mathrm{MOH}$ policies and procedures for supplying medicines to these lower-level health facilities did not include CVD medicines. For example, the Kenya Essential Medicines List (KEML) 2016 and previous versions limited CVD and diabetes medicines to be stocked only in level 4 facilities or higher. ${ }^{25}$ All seven antihypertensive medications (ie, amlodipine, carvedilol, enalapril, hydralazine, hydrochlorothiazide, losartan, methyldopa) and all antidiabetic medications (ie, metformin and insulin preparations) had only been designated to be used in level 4 or higher. ${ }^{25}$ Thus, health facilities in levels 1-3 did not have a supply of these medicines prior to the establishment of our RFP programme. Therefore, level 1-3 facilities historically have never stocked CVD and diabetes medicines. Because the demand for CVD medicines at these facilities had historically not been met, the utilisation of the RFP framework as a supply chain for these facilities was justified. ${ }^{2} 171825$ We secured the approval of the Kenya MOH, local leadership and facility administrators to integrate CVD and diabetes clinical services as well as essential medications into the lower primary care-level facilities. As such, the RFP was also permitted to supply essential medications for these conditions at the appropriate lower levels to ensure medication access for patients. However, the patient volumes at each of these lower-level facilities were not sufficient to sustain a full RFP as described above in Models 1 and 2.

The RFP Model 3 was therefore employed for these low-volume facilities, in which dispensaries were supplied with a limited formulary of CVD medications. Model 3 facilities got drugs procured indirectly through regional Model 1 and 2 RFPs. In a few facilities, clinical officers or nurses were too overwhelmed to dispense and maintain the inventory of RFP medicines. For these facilities, pharmaceutical technologists from the AMPATH CDM programme would accompany clinicians on clinic days to the facility and dispensed the medicines from tackle boxes stocked from the nearest Model 1 or 2 RFP. Small quantities of the medicines were retained at the facility in the event that patients dropped in for refills before the next clinic day. Because of the small quantities of medicines and the fact that they were managed by officers-in-charge of the facilities, there were no physical and parallel pharmacies opened in these facilities. Medications were kept in tackle boxes or in a separate area within the existing government pharmacies, and medicine inventory audits were conducted by the health facilities on a needs-based schedule. As of 2018, this model was being used in 50 facilities, mostly dispensaries and some health centres. These facilities had 11239 patients who were hypertensive and 2598 patients who were diabetic cumulatively enrolled into care between 2013 and 2018 .

\section{Supply of CVD medications across RFP models}

In 2018, a total of 5793981 CVD and diabetes medicine units (ie, tablets, capsules, vials) were supplied to the RFPs and purchased by patients across all three RFP models and across all levels of the health system in western Kenya (figure 1). RFP Model 2 supplied the highest number of 


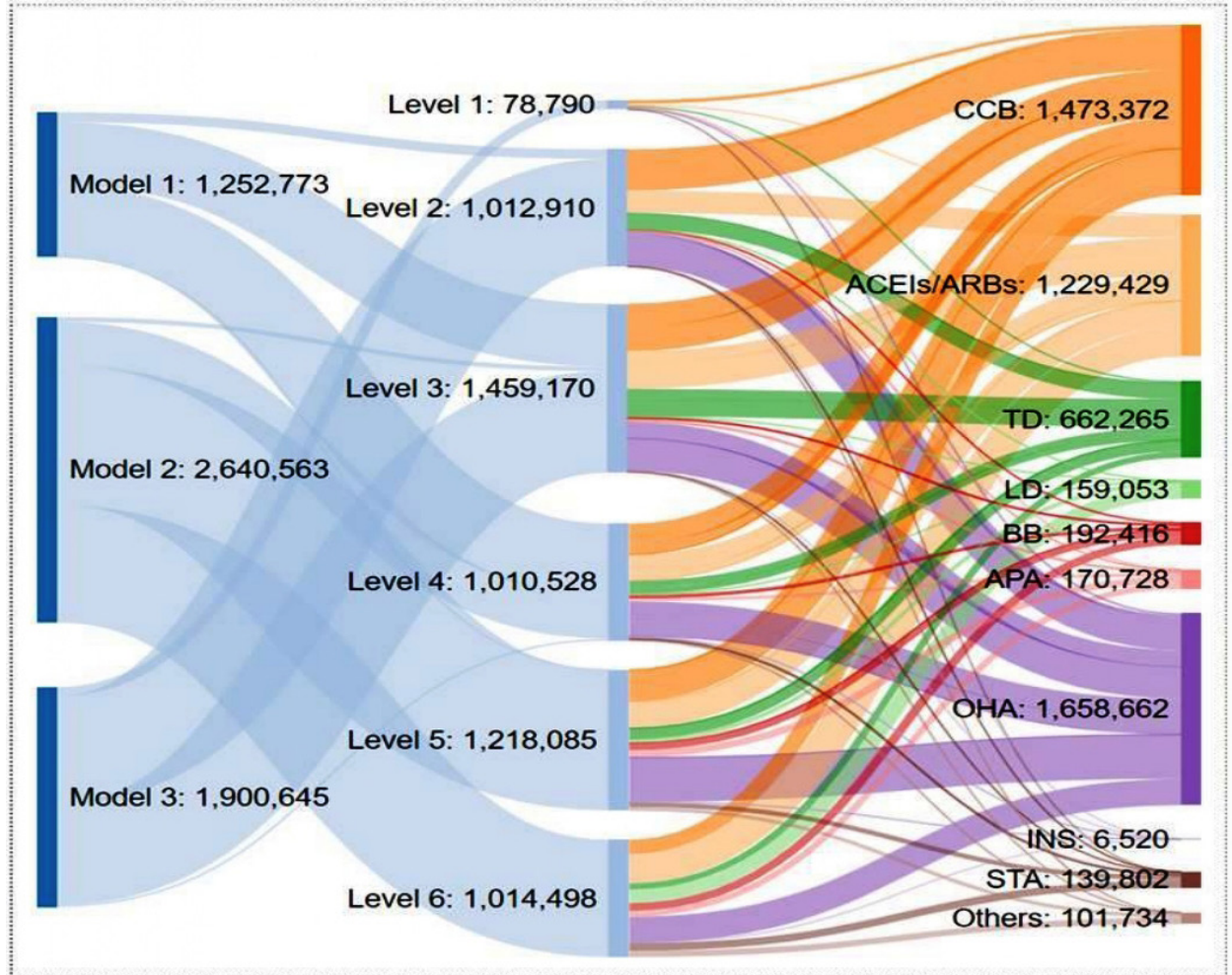

Figure 1 A schematic description of the flow of RFP-supplied CVD medications across different levels of health facilities. The above numbers represent medication units (ie, tablets, capsules or vials for insulin). Model 1=community-managed RFPs, Model 2=AMPATH-managed RFPs, Model 3=facility-managed RFPs. Level 1=community-based care program, Level 2=dispensaries, Level 3=health centres, Level 4=subcounty hospitals, Level 5=county hospitals, Level 6=tertiary referral hospitals. ACEls, angiotensin-converting enzymes inhibitors; AMPATH, The Academic Model Providing Access to Healthcare; APA, antiplatelet agents; ARBs, angiotensin-II receptor blockers; BB, beta blockers; CCB, calcium channel blockers; CVD, cardiovascular disease; INS, insulin; LD, loop diuretics; OHA, oral hypoglycaemia agents; RFP, revolving fund pharmacy; STA, statin; TD, thiazide diuretics.

medicines (2 640563 ), primarily to county and tertiary referral hospitals (levels 5 and 6). RFP Model 3 supplied the second highest number of medicines (1 900 645), primarily to the community-based care programme, dispensaries and health centres (levels 1, 2 and 3). Last, RFP Model 1 supplied 1252773 medicine units primarily to dispensaries, health centre and subcounty hospitals (levels 2, 3 and 4). The RFPs supplied a total of 22 different categories of CVD medicines: calcium channel blockers, thiazide diuretics, loop diuretics, angiotensinconverting enzymes inhibitors/angiotensin II receptor blockers, beta blockers, antiplatelet agents, statins, oral diabetes medications, insulin and other CVD medicines (cardiac glycosides, potassium-sparing diuretic and fixeddose combination CVD medicines) (table 2).

\section{Availability of tracer CVD medications across different levels of health facilities and RFP models}

As recommended by the Kenya $\mathrm{MOH}$, eight tracer CVD medicines (nifedipine, hydrochlorothiazide, enalapril, furosemide (intravenous injection solution and tablets), metformin, glibenclamide and insulin) were selected and tracked in 2018 to determine how consistently available essential CVD medicines were at all Model 1 and 2 RFP sites. ${ }^{26}$ These eight medicines were selected because they were represented on the KEML (2018), the Kenya National
Guidelines for Cardiovascular Disease Management (2018), the National Clinical Guidelines for Management of Diabetes (2010) and the local AMPATH guidelines for management of hypertension and diabetes (2018). Overall, by health system level, a majority of tracer medicines were present $94 \%-100 \%$ of the time at health facilities across levels 2-6 (figure 2). The availability of insulin (Humulin $70 / 30$ ) at levels 5 and 6 were $97 \%$ and $100 \%$, respectively, and $81 \%-85 \%$ at levels $2-4$. These results were consistent with the appropriateness of insulin prescribing practices in Kenya, being more appropriate at the county (level 5) and referral (level 6) hospitals where blood sugar monitoring for patients could be more regularly done. By RFP model, availability was also consistently above $95 \%$ in both RFP models 1 and 2 (figure 3). One exception was injectable furosemide $20 \mathrm{mg} / 2 \mathrm{~mL}$ being available at $88 \%$, a relatively lower rate in Model 2. This was due to one facility with low availability that impacted the overall the average value for Model 2.

\section{Setting up cost, running cost, and patient cost associated with each RFP model}

Using financial reports collected when each RFP was established and in 2018, we compiled a detailed cost description to compare RFP model-specific average cost per individual RFPs as well as total cost for all 


\begin{tabular}{|c|c|c|}
\hline $\begin{array}{l}\text { Pharmacological } \\
\text { category }\end{array}$ & Abbreviation & Example \\
\hline Calcium channel blockers & CCB & $\begin{array}{l}\text { Amlodipine } \\
\text { Nifedipine } \\
\text { Felodipine }\end{array}$ \\
\hline Thiazide diuretics & TD & Hydrochlorothiazide \\
\hline Loop diuretics & LD & Furosemide \\
\hline $\begin{array}{l}\text { Angiotensin-converting } \\
\text { enzymes inhibitors/ } \\
\text { Angiotensin-II receptor } \\
\text { blockers }\end{array}$ & ACEls/ARBs & $\begin{array}{l}\text { Enalapril } \\
\text { Losartan }\end{array}$ \\
\hline Beta blockers & BB & $\begin{array}{l}\text { Atenolol } \\
\text { Metoprolol } \\
\text { Propranolol } \\
\text { Carvedilol }\end{array}$ \\
\hline Antiplatelet agents & APA & $\begin{array}{l}\text { Aspirin } \\
\text { Clopidogrel }\end{array}$ \\
\hline Statins & STA & Atorvastatin \\
\hline Oral diabetes medications & $\mathrm{OHA}$ & $\begin{array}{l}\text { Metformin } \\
\text { Glibenclamide }\end{array}$ \\
\hline Insulin & INS & $\begin{array}{l}\text { Insulin Lispro } \\
\text { Insulin NPH } \\
\text { Insulin } 70 / 30\end{array}$ \\
\hline Others & Others & $\begin{array}{l}\text { Digoxin } \\
\text { Spironolactone } \\
\text { Lisinopril/ } \\
\text { hydrochlorothiazide }\end{array}$ \\
\hline
\end{tabular}

CVD, cardiovascular disease; RFP, revolving fund pharmacy.

model-specific RFPs. Table 3 summarises the cost for individual RFPs, the total cost for each RFP model and the cost per patient. The 'setting up cost' to start an RFP was $\$ 4100$ per RFP for Models 1 and 2 , and $\$ 110$ per RFP in Model 3. Annual running costs were $\$ 5820$ per RFP in Model 1, $\$ 6900$ per RFP for Model 2 and $\$ 672$ per RFP in Model 3. Due to differences in the total number of RFPs per model as summarised above, the total setup and running costs were highest for Model 1, followed by Model 2, then Model 3. Using 2018 running cost data as well as the number of medication units dispensed to patients in 2018, we estimated the annual programme running cost per patient served. Our calculations yielded an annual cost of approximately $\$ 25$ per patient in Model 1 , \$6.7 per patient in Model 2 and $\$ 6.5$ per patient in Model 3.

\section{DISCUSSION}

This paper describes the evolution of our RFP programme to increase access to essential CVD medications for patients across different levels of the public sector healthcare system in western Kenya. The RFP models evolved alongside the Kenya MOH's and the AMPATH CDM's efforts to decentralise and expand quality and affordable CVD care to all patients within the public sector in western Kenya, particularly in remote geographical regions where CVD care and medications had never been delivered before. Our experience with the various RFP models illustrates that by staying adaptable, nimble and contextualised to each of our patient populations and the environment in which the RFP was being implemented, we were able to ensure medication availability for different levels of care and care needs.

The successful scalability of each of our RFP model in the appropriate setting depended on three key components which can be summarised as follows: (1) our ability to define pharmaceutical gaps for CVD care by focusing on the patients' needs, (2) our priority to create local adoption mechanisms by establishing governance and engaging key stakeholders early in the process and (3) our efforts to create support systems and ensure sustainability by developing affordable patient copays, waivers and accountability mechanisms through inventory, financial and accounting systems. In addition, all revenues remained within our funding pool to sustain and expand more RFPs to other geographical locations to

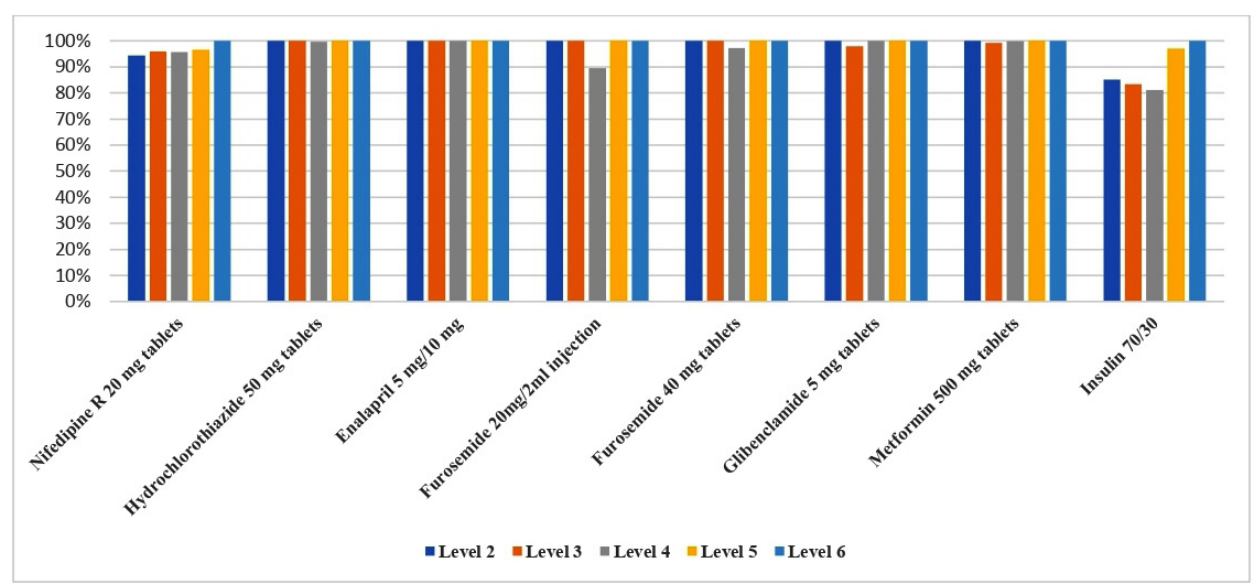

Figure 2 Average availability of tracer CVD medicines across different levels of health facilities for RFP Model 1 (communitymanaged RFPs) and Model 2 (AMPATH-managed RFPs). Level 2=dispensaries, Level 3=health centres, Level 4=subcounty hospitals, Level $5=$ county hospitals, Level $6=$ tertiary referral hospitals. AMPATH, The Academic Model Providing Access to Healthcare; CVD, cardiovascular disease; RFP, revolving fund pharmacy. 


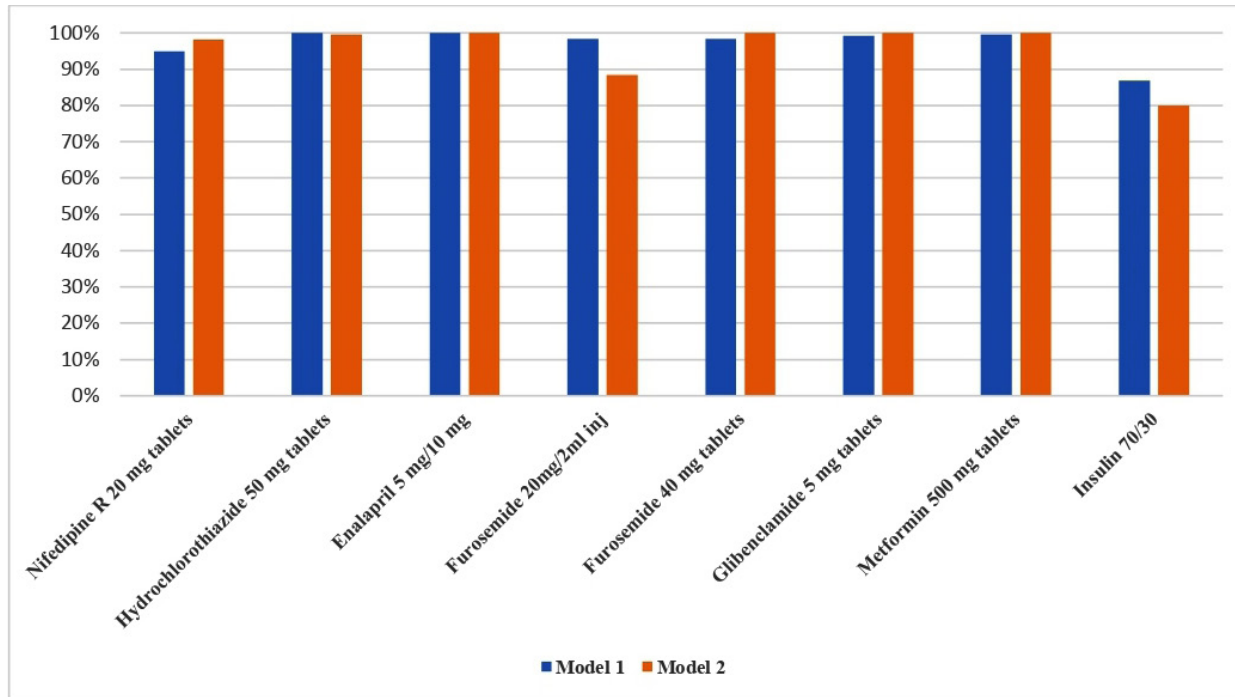

Figure 3 Average availability of tracer CVD medicines across RFP Model 1 (community-managed RFPs) and Model 2 (AMPATH-managed RFPs). AMPATH, The Academic Model Providing Access to Healthcare; CVD, cardiovascular disease; RFP, revolving fund pharmacy.

support patients. This would not have been possible without predefined accountability mechanisms such as the early establishment of governance and memoranda of understanding with key stakeholders, scheduled medicine inventory reports as well as financial and accounting reports. These scale-up strategies are similar to what have been described in previous literature and frameworks. ${ }^{27}$ From a sustainability standpoint, all three RFP models have made tremendous progress towards self-sustainability over the past decade, as demonstrated through the expansion of the model from 3 pilot sites to 72 health facilities supported by the RFP programme; the revenue recovered from drugs sold to maintain our current operation and continuous expansion; and the cost-sharing agreements between the Ministry of Health, the local health facilities, and AMPATH/RFP.

We presented the three RFP models as distinct and independent of each other; however, there is considerable overlap in the infrastructure on which each model relies. It is worth noting that the implementation of the original community-managed RFP model (ie, Model 1) was essentially a prerequisite for the development of alternative RFP models (ie, models 2 and 3) in the following years. In addition, by strategically leveraging a network of RFPs that we have built across the entire health system, our programme has the unique advantage to conduct coordinated redistribution of medication stocks between RFPs during the events of unplanned stock-outs or overstocks. Our ability to adapt to urgent supply chain issues such as these ensures rational medication allocation, adequate medications and other supplies to manage patients from the healthcare providers' standpoint, and consistent access to CVD medications from the patients' perspective. The lesson that we have learnt from implementing three different RFP models over the past 10 years has been that each model has its own advantages and disadvantages, and we must continue to stay nimble and modify as needed to determine which model might work best for the setting in which we are operating.

Through our network of RFPs, we were able to consistently and adequately supply CVD medications to meet the demand of our patients. In the year of 2018 alone, we supplied close to 6 million medication units to patients who would otherwise not have had access to affordable CVD medications. This quantity of medications is equivalent to supplying approximately 16000 patients at least one medication unit per day for the entire year. Critical to being able to accomplish this was the utilisation of core supply chain management strategies including pull strategies (ie, medications provided are driven by our patients' demand) and push strategies (ie, ability to forecast demand based on an understanding of local needs). As a result, we have been able to increase availability of generic CVD medications from the historical $30 \%$ or less to $90 \%$ or higher across all levels of the health system.

We explicitly described the programme's operational costs in detail, per RFP and specific to each model. By doing so, our goal was to widely disseminate useful and practical information to other programmes around the world that may be looking into replicating this innovative supply chain model. Furthermore, this cost data profile serves as a benchmark for future comparison for quality improvement within our own programme as well as for other similar supply chain programmes in similar LMIC settings. Finally, these cost data can be helpful in providing local government with cost information to better invest and support an adequate government-led supply chain system. We recognise, however, that these programmatic cost data do not necessarily reflect affordability from the patient's perspective. More economic analyses will be required to better understand patient-experienced costs. It is notable that, in Kenya (as in other LMICs), there has been a deliberate move towards universal healthcare, ${ }^{22}$ including a benefits package that includes outpatient 
Table 3 Programme setting up cost, programme running cost and programme running cost per patient served across RFP models (in US\$)

\begin{tabular}{|c|c|c|c|c|c|c|c|c|}
\hline \multirow[b]{2}{*}{ Category } & \multirow[b]{2}{*}{ Type of cost } & \multirow[b]{2}{*}{ Cost description } & \multicolumn{2}{|c|}{$\begin{array}{l}\text { Model } 1 \\
\text { Community-managed } \\
\text { RFP } \\
\end{array}$} & \multicolumn{2}{|c|}{$\begin{array}{l}\text { Model } 2 \\
\text { AMPATH-managed } \\
\text { RFP }\end{array}$} & \multicolumn{2}{|c|}{$\begin{array}{l}\text { Model } 3 \\
\text { Facility-managed RFP }\end{array}$} \\
\hline & & & $\begin{array}{l}\text { Cost per } \\
\text { RFP }\end{array}$ & Total cost & $\begin{array}{l}\text { Cost per } \\
\text { RFP }\end{array}$ & Total cost & $\begin{array}{l}\text { Cost per } \\
\text { RFP }\end{array}$ & Total cost \\
\hline \multirow[t]{3}{*}{$\begin{array}{l}\text { Setting up } \\
\text { costs (one- } \\
\text { time costs) }\end{array}$} & Renovation & $\begin{array}{l}\text { Identified rooms are renovated } \\
\text { to meet specifications of a } \\
\text { pharmacy }\end{array}$ & 2000 & 30000 & 2000 & 14000 & $\mathrm{n} / \mathrm{a}$ & $\mathrm{n} / \mathrm{a}$ \\
\hline & Seed stock & $\begin{array}{l}\text { Initial drug stock plus } \\
\text { miscellaneous pharmacy } \\
\text { supplies (stationery, pill } \\
\text { counters and so on) }\end{array}$ & 2000 & 30000 & 2000 & 14000 & 100 & 5000 \\
\hline & Travel & $\begin{array}{l}\text { Meetings with facility } \\
\text { leadership, oversight of } \\
\text { renovations, delivery of seed } \\
\text { stock of drugs }\end{array}$ & 100 & 1500 & 100 & 700 & 10 & 500 \\
\hline \multicolumn{3}{|c|}{ Total programme setting up cost (one-time cost) } & 4100 & 61500 & 4100 & 28700 & 110 & 5500 \\
\hline \multirow{5}{*}{$\begin{array}{l}\text { Running } \\
\text { costs (per } \\
\text { year) }\end{array}$} & Personnel & Pharmaceutical technologist & 2400 & 36000 & 3000 & 21000 & 240 & 12000 \\
\hline & Supervision & $\begin{array}{l}\text { Inventory management, } \\
\text { supervision and mentorship of } \\
\text { site staff }\end{array}$ & 720 & 10800 & 720 & 5040 & 120 & 6000 \\
\hline & Transportation & $\begin{array}{l}\text { Transportation of supplies, } \\
\text { drugs, supervisory personnel }\end{array}$ & 900 & 13500 & 900 & 6300 & 72 & 3600 \\
\hline & Waivers & $\begin{array}{l}\text { For indigent patients who are } \\
\text { unable to afford medications }\end{array}$ & 360 & 5400 & 360 & 2520 & Minimal & Minimal \\
\hline & $\begin{array}{l}\text { Programme } \\
\text { leadership and } \\
\text { management }\end{array}$ & $\begin{array}{l}\text { Overall strategy planning, } \\
\text { oversight, audit, procurement } \\
\text { and financial management }\end{array}$ & 1440 & 21600 & 1920 & 13440 & 240 & 12000 \\
\hline \multicolumn{3}{|c|}{ Total programme running cost (per year) } & 5820 & 87300 & 6900 & 48300 & 672 & 33600 \\
\hline \multicolumn{3}{|c|}{ Quantity of medication units supplied (2018) } & \multicolumn{2}{|c|}{1252773 units } & \multicolumn{2}{|c|}{2640563 units } & \multicolumn{2}{|c|}{1900645 units } \\
\hline \multicolumn{3}{|c|}{$\begin{array}{l}\text { Estimated number of patients receiving at least one } \\
\text { medication unit per day for the entire year* }\end{array}$} & \multicolumn{2}{|c|}{3432 patients } & \multicolumn{2}{|c|}{7234 patients } & \multicolumn{2}{|c|}{5207 patients } \\
\hline \multicolumn{3}{|c|}{ Programme running cost per patient served (per year) $\dagger$} & \multicolumn{2}{|l|}{25} & \multicolumn{2}{|l|}{6.7} & \multicolumn{2}{|l|}{6.5} \\
\hline \multicolumn{3}{|c|}{$\begin{array}{l}\text { Programme average running cost per patient served (per } \\
\text { year) }\end{array}$} & 10.6 & & & & & \\
\hline
\end{tabular}

*Estimated number of patients receiving at least one medication unit per day for the entire year=Quantity of medication units supplied in $2018 \div 365$ days.

†Programme running cost per patient served=(Total running cost per model per year) $\div$ (Estimated number of patients receiving at least one medication unit per day for the entire year).

AMPATH, The Academic Model Providing Access to Healthcare; RFP, revolving fund pharmacy.

chronic disease medications, which represents the key pillar to offset the medication cost realities that are a key hindrance to adherence in low-resource settings.

Finally, our experiences with RFPs have highlighted other persistent barriers that need to be addressed, such as transportation costs, opportunity cost of missed work and distance from health facilities. Building on the foundation of our RFPs, we are currently testing an innovative model of CVD medication refills whereby trained peers with hypertension serve as drug delivery agents. In addition to overcoming the above patient barriers, the trained peers can provide psychosocial support, perform simple screening for medication adherence, elicit patient-reported adverse drug effects and health-seeking behaviours specific to chronic asymptomatic CVD, all of which can be immediately relayed to clinicians for appropriate action. ${ }^{28}$ Our existing RFPs can be leveraged to test new supply chain models to improve access from both the supply and demand side for CVD medicines. ${ }^{2}$

\section{Limitations}

We acknowledge several key limitations to consider. First, we were not able to analyse the medicine availability profile for Model 3 RFPs due to the lack of consistent reports from these sites. However, because these RFPs received their medication supplies from nearby Model 1 or Model 2 RFPs, we can extrapolate the assumption that Model 3 availability was similar to that seen in Model 1 and 2 (approximately $90 \%$ or above). Another key limitation is that discrete patient-specific data could not be analysed to show more detailed trends in terms of number of patient visits, patient-specific medication refills, 
adherence patterns and respective clinical outcomes within the different models. While clinical outcomes could not be described in this paper, AMPATH has a large body of previously published papers describing the clinical effectiveness of the overarching CDM care model, a central component of which includes the RFP approach to ensuring medication availability. ${ }^{13}{ }^{29-31}$ Last, our assessment was done from the perspective of the patient and their needs. While it is possible that introducing a backup pharmacy system may have unintended negative consequences on the impetus for improving the $\mathrm{MOH}$ pharmacies, it is our hope that this analysis provides the evidence to support the ongoing advocacy and adoption of RFP supply chain principles to ultimately improve the MOH supply chain systems.

\section{CONCLUSION}

In this paper, we have described our implementation experience and provide consumption and availability data as well as initial and maintenance costs per RFP model. We have described our iterative and contextualised solutions that adapt to local conditions and settings. We believe the RFP model has the potential to significantly improve access to CVD medicines for patients and can be adapted and implemented in other similar lowresource settings.

\section{Author affiliations}

${ }^{1}$ Pharmacy Practice, Purdue University College of Pharmacy, Indianapolis, IN, USA ${ }^{2}$ Pharmacology and Toxicology, Moi University College of Health Sciences, Eldoret, Kenya

${ }^{3}$ Academic Model Providing Access to Healthcare (AMPATH), Eldoret, Kenya

${ }^{4}$ Pharmacy, Moi Teaching and Referral Hospital, Eldoret, Kenya

${ }^{5}$ Medicine, Moi University College of Health Sciences, School of Medicine, Eldoret, Kenya

${ }^{6}$ Family Medicine, Moi University College of Health Sciences, School of Medicine, Eldoret, Kenya

${ }^{7}$ Pharmacy, Kericho County Referral Hospital, Kericho, Kenya

${ }^{8}$ Department of Population Health, New York University Grossman School of Medicine, New York, NY, USA

Twitter Rajesh Vedanthan @rvedanthan

Acknowledgements We thank Eunice Kosgei, Phelix Were, Kenneth Too, James Kamadi, Rogers Boit, Maureen Tuei, Moses Rotich, Kennedy Nabongo, Sabinah Atieno, Carren Soita, Amos Kiplagat, Caren Chepngetich and Elizabeth 0'Hara for their direct technical assistance and intellectual discussions over the years to support the Revolving Fund Pharmacy programme. We also thank Abbott Diabetes Care for providing glucose testing supplies, Eli Lilly and Company for donating insulin, AstraZeneca and Abvie for providing financial support to the CDM programme and the Pfizer Global Health Fellows programme for providing volunteer staff. The work described in this article was supported in part by the President's Emergency Plan for AIDS Relief through the U.S. Agency for International Development under the terms of Cooperative Agreement No. AID-623-A-12-0001.

Contributors DNT and IM conceived and designed the work; acquired, analysed and interpreted the data; drafted, revised and approved the final manuscript. RV and SP conceived and designed the work; interpreted the data; drafted, revised and approved the final manuscript. BN conceived and designed the work; interpreted the data; drafted and approved the final manuscript. JK and JL conceived the work; interpreted the data; revised and approved the final manuscript. ET conceived and designed the work; interpreted the data; drafted and approved the final manuscript.

Funding The authors have not declared a specific grant for this research from any funding agency in the public, commercial or not-for-profit sectors.
Disclaimer The contents of this article are the sole responsibility of AMPATH and do not necessarily reflect the views of USAID or the US government.

Competing interests Sonak Pastakia serves as a consultant for Abbott and Becton Dickinson on work unrelated to the study being presented here. The other authors declare that they have no competing interests.

Patient and public involvement Patients and/or the public were not involved in the design, or conduct, or reporting, or dissemination plans of this research.

Patient consent for publication Not required.

Provenance and peer review Not commissioned; externally peer reviewed.

Data availability statement All data relevant to the study are included in the article. Original data are available on request.

Open access This is an open access article distributed in accordance with the Creative Commons Attribution Non Commercial (CC BY-NC 4.0) license, which permits others to distribute, remix, adapt, build upon this work non-commercially, and license their derivative works on different terms, provided the original work is properly cited, appropriate credit is given, any changes made indicated, and the use is non-commercial. See: http://creativecommons.org/licenses/by-nc/4.0/.

\section{ORCID iDs}

Dan N Tran http://orcid.org/0000-0002-8332-8196

Rajesh Vedanthan http://orcid.org/0000-0001-7138-2382

Sonak Pastakia http://orcid.org/0000-0003-4259-695X

\section{REFERENCES}

1 Khatib R, McKee M, Shannon $\mathrm{H}$, et al. Availability and affordability of cardiovascular disease medicines and their effect on use in highincome, middle-income, and low-income countries: an analysis of the pure study data. Lancet 2016;387:61-9.

2 Tran DN, Njuguna B, Mercer T, et al. Ensuring patient-centered access to cardiovascular disease medicines in low-income and middle-income countries through Health-System strengthening. Cardiol Clin 2017;35:125-34.

3 Daivadanam M, Ingram M, Sidney Annerstedt K, et al. The role of context in implementation research for non-communicable diseases: Answering the 'how-to' dilemma. PLoS One 2019;14:e0214454.

4 GBD 2016 Causes of Death Collaborators. Global, regional, and national age-sex specific mortality for 264 causes of death, 19802016: a systematic analysis for the global burden of disease study 2016. Lancet 2017;390:1151-210.

5 Roth GA, Huffman MD, Moran AE, et al. Global and regional patterns in cardiovascular mortality from 1990 to 2013 . Circulation 2015;132:1667-78.

6 Mutowo MP, Lorgelly PK, Laxy M, et al. The hospitalization costs of diabetes and hypertension complications in Zimbabwe: estimations and correlations. J Diabetes Res 2016;2016:9

7 Mutyambizi C, Pavlova M, Chola L, et al. Cost of diabetes mellitus in Africa: a systematic review of existing literature. Global Health 2018;14:3.

8 Walker IF, Garbe F, Wright J, et al. The economic costs of cardiovascular disease, diabetes mellitus, and associated complications in South Asia: a systematic review. Value Health Reg Issues 2018;15:12-26.

9 Cinelli M, Coles SR, Kirwan K. Analysis of the potentials of multi criteria decision analysis methods to conduct sustainability assessment. Ecol Indic 2014:46:138-48.

10 Fullman N, Barber RM, Abajobir AA, et al. Measuring progress and projecting attainment on the basis of past trends of the health-related sustainable development goals in 188 countries: an analysis from the global burden of disease study 2016. Lancet 2017;390:1423-59.

11 Gheorghe A, Griffiths U, Murphy A, et al. The economic burden of cardiovascular disease and hypertension in low- and middle-income countries: a systematic review. BMC Public Health 2018;18:975.

12 Checkley W, Ghannem H, Irazola V, et al. Management of noncommunicable disease in low- and middle-income countries. Glob Heart 2014:9:431-43.

13 Barasa FA, Vedanthan R, Pastakia SD, et al. Approaches to sustainable capacity building for cardiovascular disease care in Kenya. Cardiol Clin 2017;35:145-52.

14 Binanay CA, Akwanalo CO, Aruasa W, et al. Building sustainable capacity for cardiovascular care at a public hospital in Western Kenya. J Am Coll Cardiol 2015;66:2550-60. 
15 Wirtz VJ, Kaplan WA, Kwan GF, et al. Access to medications for cardiovascular diseases in low- and middle-income countries. Circulation 2016;133:2076-85.

16 Husain MJ, Datta BK, Kostova D, et al. Access to cardiovascular disease and hypertension medicines in developing countries: an analysis of essential medicine Lists, price, availability, and affordability. J Am Heart Assoc 2020;9:e015302.

17 Vedanthan R, Kamano JH, Bloomfield GS, et al. Engaging the entire care cascade in Western Kenya: a model to achieve the cardiovascular disease secondary prevention roadmap goals. Glob Heart 2015;10:313-7.

18 Manji I, Manyara SM, Jakait B, et al. The revolving fund pharmacy model: backing up the Ministry of health supply chain in Western Kenya. Int J Pharm Pract 2016;24:358-66.

19 Ali GKM. How to establish a successful revolving drug fund: the experience of Khartoum state in the Sudan. Bull World Health Organ 2009;87:139-42.

20 Garner P. The Bamako initiative. BMJ 1989;299:277-8.

21 Einterz RM, Kimaiyo S, Mengech HNK, et al. Responding to the HIV pandemic: the power of an academic medical partnership. Acad Med 2007:82:812-8.

22 Mercer T, Gardner A, Andama B, et al. Leveraging the power of partnerships: spreading the vision for a population health care delivery model in Western Kenya. Global Health 2018;14:44..

23 Pastakia SD, Ali SM, Kamano JH, et al. Screening for diabetes and hypertension in a rural low income setting in Western Kenya utilizing home-based and community-based strategies. Global Health 2013;9:21.
24 Pastakia SD, Manyara SM, Vedanthan R, et al. Impact of bridging income generation with group integrated care (BIGPIC) on hypertension and diabetes in rural Western Kenya. J Gen Intern Med 2017;32:540-8.

$25 \mathrm{MOH}$. Kenya essential medicines list 2016 Republic of Kenya, 2016. Available: http://www.health.go.ke/wp-content/uploads/2016/07/ KEML-2016Final.pdf [Accessed 7 Aug 2020].

$26 \mathrm{MOH}$. Kenya harmonized health facility assessment 2018/2019 Republic of Kenya, 2018. Available: https://www.health.go.ke/wpcontent/uploads/2020/01/KHFA-2018-19-Popular-version-reportFinal-.pdf [Accessed 15 Sep 2020].

27 Barker PM, Reid A, Schall MW. A framework for scaling up health interventions: lessons from large-scale improvement initiatives in Africa. Implementation Sci 2015;11:12

28 Naanyu V, Vedanthan R, Kamano JH, et al. Barriers influencing linkage to hypertension care in Kenya: qualitative analysis from the lark hypertension study. J Gen Intern Med 2016;31:304-14.

29 Osetinsky B, Genberg BL, Bloomfield GS, et al. Hypertension contro and retention in care among HIV-infected patients: the effects of colocated HIV and chronic noncommunicable disease care. J Acquir Immune Defic Syndr 2019;82:399-406.

30 Osetinsky B, Hontelez JAC, Lurie MN, et al. Epidemiological and health systems implications of evolving HIV and hypertension in South Africa and Kenya. Health Aff 2019;38:1173-81.

31 Pastakia SD, Nuche-Berenguer B, Pekny CR, et al. Retrospective assessment of the quality of diabetes care in a rural diabetes clinic in Western Kenya. BMC Endocr Disord 2018;18:97. 